\title{
Dynamic Simulation of Absorber for Solar Adsorption Refrigerator: A Validated Numerical Model
}

\author{
Rodolfo Echarri1 ${ }^{1,2}$, Inna Samsón ${ }^{3}$, Andrei Gariaev4 ${ }^{\text {, Andrés Sartarelli1 }}$ \\ ${ }^{1}$ Instituto del Desarrollo Humano, Universidad Nacional de General Sarmiento, Buenos Aires, Argentina \\ ${ }^{2}$ Consejo Nacional de Investigaciones Científicas y Técnicas (CONICET), Buenos Aires, Argentina \\ ${ }^{3}$ Laboratorio de Energías Alternativas, Instituto Tecnológico de Santo Domingo, Santo Domingo, Dominican \\ ${ }^{4}$ Department of Heat and Mass Transfer Processes and Systems, Moscow Power Engineering Institute, Moscow, Russia \\ Email: recharri@ungs.edu.ar, innasamt@gmail.com, GariayevAB@mpei.ru, asartare@ungs.edu.ar
}

How to cite this paper: Echarri, R., Samsón, I., Gariaev, A. and Sartarelli, A. (2017) Dynamic Simulation of Absorber for Solar Adsorption Refrigerator: A Validated Numerical Model. Energy and Power Engineering, 9, 464-477.

https://doi.org/10.4236/epe.2017.98030

Received: July 11, 2017

Accepted: August 12, 2017

Published: August 15, 2017

Copyright $\odot 2017$ by authors and Scientific Research Publishing Inc. This work is licensed under the Creative Commons Attribution International License (CC BY 4.0).

http://creativecommons.org/licenses/by/4.0/

(c) (i) Open Access

\begin{abstract}
In this work, a numerical model is presented that describes the transfer of heat and mass inside a cylindrical regenerator of a solar adsorption refrigerator that uses the methanol/activated-carbon refrigerant pair. This model is based on the equations of mass conservation, energy conservation, Darcy's law and the balance model between sorbate and sorbent given by the Dubinin-Astakhov's equation. On the other hand, the linear driving force (LDF) model is used to describe the rate of desorption. In the developed model, the spatial variation of methanol vapor pressure within the activated carbon bed is taken into account and, as one of the boundary conditions, the temperature is used at the external surface of the absorber measured experimentally along the day. Using the developed model, the temperature, pressure and concentration of methanol were calculated; both inside the grains of carbon and in the space between the grains, as a function of time. The algorithm was validated comparing the numerical results with the experimental data, obtaining a satisfactory concordance.
\end{abstract}

\section{Keywords}

Adsorption, Solar Ice Maker, Methanol Activated Carbon

\section{Introduction}

The continuous increase of energy consumption in the world coupled with the limited amount of resources, creates the need of searching new energy sources. Because of this, in the last three decades, the refrigeration systems have been 
paid attention to that use the adsorption phenomenon for their operation. In particular, adsorption refrigerators can use both waste heat and solar energy in the regeneration stage of the adsorbent, and that makes it more attractive for its use in areas with a hot climate and difficult access of electrical lines.

If it is decided to use the adsorption phenomenon to produce cold, there are several options to choose the sorbent-sorbate pair, such as: zeolite-water, silica gel-water, activated carbon-ammonia, activated carbon-methanol. The principle of operation is based on the variability of the adsorptive properties of the sorbent with the temperature. To produce more cold, it is pertinent to find a sorbent that has the greatest variation of adsorption capacity for the range of temperatures to which the device would be exposed. Different researchers analyzed the potential of such pairs as silica gel-water, zeolite-water, activated carbon-methanol and activated carbon-ammonia [1]-[17] in cooling systems.

Different authors developed experimental prototypes and studied their behavior. For example Tchernev [3] analyzes the natural zeolites, in addition constructs an experimental device that uses solar energy with $50 \mathrm{~kg}$ of zeolite for each square meter of area [4], whereas other researchers [5] [6] use synthetic zeolite. In particular Tubreoumya et al. [14] have developed a simulation of the mentioned pair comparing the cycle of Clayperon with the one published by Allouhi [15] obtaining an excellent concordance. In systems using zeolite, the temperature during the desorption process must exceed $200^{\circ} \mathrm{C}$ and the adsorption temperature should be less than $80^{\circ} \mathrm{C}$. This requires the use of more complex technologies during the development and manufacture of the absorber [2] than in the case of lower temperatures of regeneration as the case of activated carbon-methanol. On the other hand, the low pressure of the water vapors makes the adsorption process slow.

The adsorptive properties of the silica gel-water pair have been studied [7]. Adsorption refrigeration systems using zeolite-water and silica gel-water are mostly used in air conditioning systems, because in those systems the sorbate is water and for reasonable efficiency, the evaporation temperature must be relatively high, for example $4^{\circ} \mathrm{C}[8]$.

When the activated carbon-ammonia pair is used during the desorption process the pressure is maintained in the order of 1.6 MPa. On the other hand, the high pressure increases the mass flow and shortens the adsorption process. Previously, experimental facilities did not find wide use mainly caused for the ammonia toxicity and its corrosivity [2]. These systems have recently attracted more attention from researchers thanks to the very high ammonia refrigerant capacity. These systems are analyzed in more detail in other works [2] [9] [11] [13].

The activated carbon-methanol pair is used in adsorption cooling systems due to the high cyclic adsorption capacity, low desorption temperature, low adsorption energy and high latent heat of methanol for the liquid to gas phase change.

In the last three decades, different groups of researchers work with adsorption cooling using the activated carbon-methanol refrigerant pair. Some groups of 
authors dedicated their efforts to the construction of experimental prototypes and analysis of their behavior [18] [19] [20] [21] [22], in [20], is also presented the experimental cycle of the solar adsorption refrigerator. Other authors construct experimental prototypes and simulate solar energy in the laboratory.

In the theoretical simulation of the processes that happen in the solar refrigerator, many authors have presented models based on the states of equilibrium, without making an analysis of the transient states and they focus on evaluating theoretically the performance of the system, determining the efficiency and COP. For example, the authors Boubakri, Guilleminot and Meunier [18] constructed a model of adsorption solar cooler with a flat solar collector, they evaluated the amount of ice that could be produced and the values of COP $(0.12-0.19)$ that could be reached by the device and did not perform an evaluation of transient processes.

Luo and Tondeur [20] in their work presented results obtained with a prototype of refrigerator with cylindrical adsorber with the exterior and interior diameters $0.06 \mathrm{~m}$ and $0.02 \mathrm{~m}$ respectively. To the outer surface of the adsorber, which contained $0.86 \mathrm{~kg}$ of activated carbon, heat was transferred by means of electric resistors with the maximum flow of $750 \mathrm{~W} / \mathrm{m}^{2}$. During the tests, a vacuum pump was used, while in the regular operation of these devices the vacuum pump is not used.

The authors Luo and Tondeur constructed a mathematical model of the absorber [20], the model is unidimensional and contains the mass and energy conservation equations written in cylindrical coordinates, and the adsorbent-adsorptive equilibrium model of Dubinin-Radushkevich. The authors assume that the pressure in the system and throughout the coal bed remains constant during the desorption and adsorption processes. These authors show experimental results and theoretical calculations for the temperature in the coal bed and the amount of desorbed methanol. In that case, the experimental and theoretical temperature curves as a function of time are close during the adsorption process, while they are not very close during the desorption process. The shape of the experimental and theoretical curves for the amount of desorbed methanol agree well, but the experimental process is finalized much earlier and significant quantitative differences are observed, reaching a 50\% error in some cases. In 2013 Qasem $y$ El-Shaarawimade an analysis of the factors that can improve the performance of this type of devices using a simulation in Matlab [16].

Other authors [23] present a model of the processes that occur in an adsorption refrigeration tube and show a comparison between the variables measured experimentally and obtained in the numerical simulation, such as temperature, pressure and the amount of methanol desorbed from the activated carbon during the desorption process. In the experiment, the authors maintain constant the temperature on the outer surface using a hot water jacket that circulates around it. The largest discrepancy is found between experimental and theoretical curves representing the amount of desorbed methanol, which is actually the most important parameter to evaluate the efficiency of the system. 
We focus on solar adsorption refrigerators that use the activated carbon-methanol refrigerant pair and that have a parabolic cylindrical collector. We performed an experimental study of the behavior of a prototype for several years and constructed a mathematical model.

In the present work, we show a model that presents several differences with the models commented before. We observed that in the mathematical models found in the literature was achieved a better fit between the experimental and the theoretical data for the adsorption process than for the desorption process.

If it is used of the adsorption phenomenon in solar cooling, the desorption process lasts considerably less time than the adsorption process. The desorption process takes place after an isosteric heating and lasts approximately 3 - 4 hours, corresponding to the hours of greatest solar radiation intensity. While the adsorption process can last the entire time interval as long as the activated carbon has temperature close to the environment, starting with isosteric cooling when the incident solar radiation decreases and then it can last all night, in other words of 8 to 15 hours, depending on the adsorptive properties of the particular activated carbon. Therefore, the most important is to achieve a design in which during the hours of exposure to the sun desorbs the largest amount of methanol possible.

For the reasons explained above, we performed the validation of the mathematical model of the refrigerator for the desorption process and achieved a good fit between the experimental and theoretical curves.

All transient mathematical models of the cylindrical solar absorber contain the mass and energy conservation equations, the ideal gas equation, and the equilibrium equation between sorbate and sorbent (Dubinin-Radushkevich or Dubinin-Astakhov equation). Several authors add to these equations the LDF model which assumes a linear dependence for the rate of the sorption process with the difference between the amount of instantaneous adsorbed methanol and the amount of methanol that would have adsorbed the coal when reaching equilibrium for the pressure and temperatures of the system for that instant. Some models consider that the pressure of the methanol vapor inside the carbon bed remains constant in the space and therefore these models do not have convective component in the conservation equations. When the pressure in the system is considered to vary in the space (within the bed of carbon), to the mentioned equations it is added equation of Darcy's law without considering the gravitational component.

Another important issue to consider when constructing the model, are the boundary conditions for Darcy's equation and for energy conservation equation. Most authors consider the temperature of the outer surface of the absorber constant over time [20] [21] [22] [23] [24]. This border condition is not accurate if you model the behavior of the solar cooler, since the solar radiation as well as the temperature changes over time. These authors validated their models in experimental devices where the absorber was placed in a medium with constant temperature. The experiment was designed to correspond to that border condition. 
However, if it is a refrigerator that would use solar energy in the regeneration stage, that border condition introduces an important error when the heating and isosteric cooling is simulated.

In the model presented in this paper, the boundary conditions for the energy conservation equation in the upper part of the cylinder were defined as a function of time using experimental measurements obtained for this purpose. The boundary condition for the Darcy equation is the pressure in the channel of the absorber. Some authors consider this as a constant pressure [20], and in the desorption stage they have an error of up to $50 \%$. We defined this boundary condition as a function of time based on experimental data.

Text styles are provided. The formatter will need to create these components, incorporating the applicable criteria that follow.

\section{Operating Principle}

The device consists of solar absorbers, condenser and evaporator Figure 1. In the solar absorber is located the activated carbon impregnated with methanol. The operating principle is based on the methanol sorption phenomena in activated carbon and the variability of the adsorptive capacity of the activated carbon with the temperature variation.

In particular, the device in question consists of a single absorber tube $1 \mathrm{~m}$ long with an outer diameter of $0.10 \mathrm{~m}$ and an inner radius of $0.03 \mathrm{~m}$ with an approximate content of $3 \mathrm{~kg}$ of activated carbon. The condenser consists of five copper tubes, $0.4 \mathrm{~m}$ long and $0.020 \mathrm{~m}$ in diameter, which are submerged in water. This is sufficient to provide the necessary heat exchange with the environment.

On the other hand, the evaporator consists of a cylindrical iron vessel $0.12 \mathrm{~m}$ in diameter and $0.20 \mathrm{~m}$ long.

The operation of the refrigerator can be divided into two stages: regeneration of activated carbon (day) and generation of cold (night). During the day, the temperature of the absorber and the activated carbon within rises, and the methanol exits the pores of the activated carbon in the form of gas. At this time the pressure in the system increases; this process corresponds to the isosteric heating of the ideal cycle diagram Figure 2.

When the pressure in the system reaches the saturation pressure value of methanol at the condenser temperature, the condensation process begins and the methanol desorption process intensifies. That corresponds to line $\mathrm{BC}$ of the diagram; isobaric desorption.

At this stage, methanol falls by gravity into the evaporator and accumulates in the evaporator.

When solar radiation decreases, the temperature of the activated carbon and the pressure in the system begins to decline; that corresponds to the process of isosteric cooling. In other words, the amount of methanol adsorbed by the activated carbon does not undergo changes (line BA of the Figure 2). When the pressure in the system drops to the saturation pressure of methanol at the 


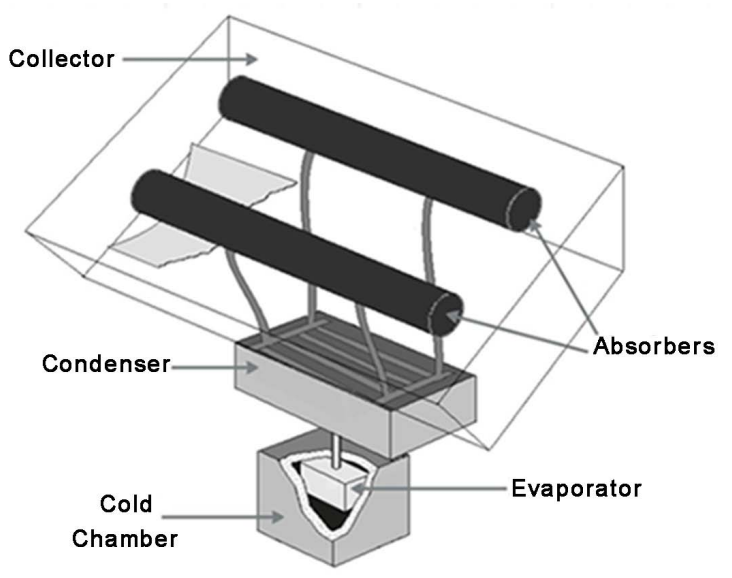

Figure 1. Scheme of solar cooling device.

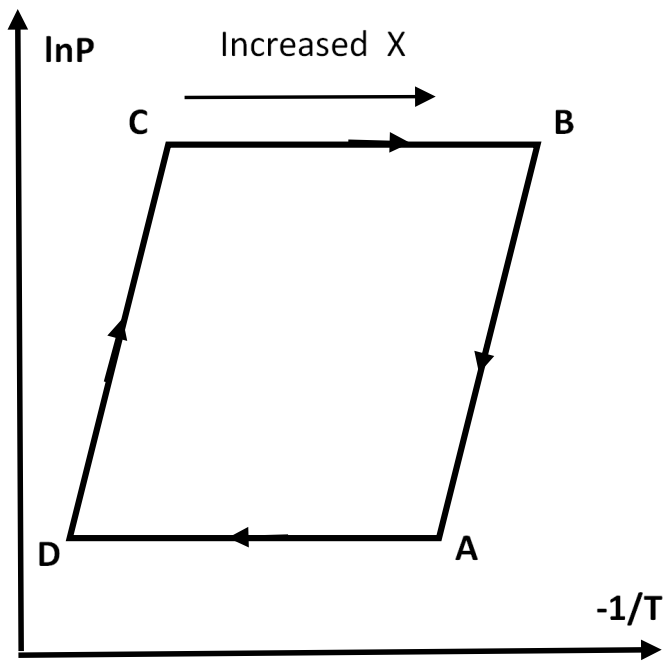

Figure 2. Ideal cycle of adsorption cooling.

evaporator temperature, the methanol adsorption process begins; the methanol evaporates producing cold in the cold chamber (line AD).

Our equipment does not have a valve that interrupts the communication between the condenser and the evaporator as it happens in most of the devices described in the literature and has been able to supply us approximately $0.5 \mathrm{~kg}$ of ice per day.

\section{Mathematical Model}

The absorber is a cylinder of length $L$, of outer radius $r_{b}$, with an empty coaxial cylindrical space of radius $r_{a}$. The space in the cylindrical ring is filled with activated carbon, while the internal space is left free for the passage of methanol in the form of gas.

A mathematical model was constructed for the cylindrical absorber. The behavior of the condenser was modeled through the pressure in the system during the regeneration stage of the activated carbon. 


\subsection{Assumptions of the Mathematical Model}

The assumptions of the mathematical model are the following:

1) The model is considered one-dimensional (radial direction) given the prevailing symmetry.

2) Methanol in gaseous form can be modeled with sufficient approximation using the ideal gas equation since the corrective terms in the Van der Waals equation are 10 - 3 with respect to the volume and 10 - 4 with respect to the pressure.

3) The equilibrium states of activated carbon and methanol are described by the Dubinin-Astakhov equation.

4) The relationship between the rate of methanol in the gaseous state and the pressure in the carbon bed is described by the Darcy equation.

5) The velocity of the adsorption and desorption processes is proportional to the difference between the instantaneous concentration of methanol adsorbed in the carbon grains and the equilibrium concentration [24] [25].

6) There is thermal equilibrium between the activated carbon grains and the surrounding gaseous methanol. In particular, this last assumption we assume valid given the result of the calculation. So far we cannot evaluate its difference with a model where both phases are not in thermal equilibrium given the difficulty to calculate the coefficient of thermal transfer between both phases.

\subsection{Constituent Equations}

The equations that constitute our model are the following:

Mass conservation equation:

$$
\epsilon \frac{\partial}{\partial t}\left(C_{g}\right)+(1-\epsilon) \rho_{c} \frac{\partial}{\partial t}(X)+\frac{\epsilon}{r} \frac{\partial}{\partial r}\left(r C_{g} v\right)=0
$$

where the first term represents the change in methanol gas concentration in the space between the activated carbon particles, the second one represents the variation of the amount of methanol adsorbed in the pores of the activated carbon particles, and the third term represents the balance between the amount of gaseous methanol entering and exiting the control volume.

Energy conservation equation:

$$
\begin{aligned}
& \epsilon \frac{\partial}{\partial t}\left(C_{g} U_{g}\right)+(1-\epsilon) \rho_{c} \frac{\partial}{\partial t}\left(U_{c}+X U_{\text {met }}+X U_{a d s}\right)+\frac{\epsilon}{r} \frac{\partial}{\partial r}\left(r C_{g} v h_{g}\right) \\
& =\frac{1}{r} \frac{\partial}{\partial t}\left(K_{e f f} r \frac{\partial T}{\partial r}\right)
\end{aligned}
$$

On the left side of this equation the first member represents the energy of the gaseous methanol that lies between the carbon granules, the second one represents the energy of the activated carbon and of the methanol adsorbed inside carbon and also the energy of sorption, adsorbed or released in the carbon volume. The third term represents the energy balance due to the movement of the gaseous methanol to and from the control volume. In the right part of the equation is represented the energy that propagates across the boundaries of the control volume by conduction. 
Darcy's law, written without taking into account the gravitational component because the latter is negligible against the frictional component.

$$
v=-\frac{K_{d}}{\mu} \frac{\partial P}{\partial r}
$$

We consider that in the space between the carbon particles, the gaseous methanol behaves like an ideal gas, and with that consideration we write the equation:

$$
P=C_{g} R T
$$

When the activated carbon is in equilibrium with the sorbate (methanol), the concentration of methanol within the activated carbon is determined using the Dubinin-Astakhov model:

$$
X_{e q}=X_{0} \mathrm{e}^{-\beta\left(T * \ln \frac{P}{P_{0}}\right)^{n}}
$$

When the concentration of instantaneous methanol $X$ within activated carbon is greater than the equilibrium concentration for the carbon temperature and the pressure in the system, the desorption process occurs, and when that concentration is less than the equilibrium concentration, occurs the adsorption process.

To describe the speed of the adsorption and desorption processes, we use the LDF model analyzed in different works [23] [24]:

$$
\frac{\partial X}{\partial t}=\frac{15 D_{0}}{R_{p}^{2}} \mathrm{e}^{\frac{E_{a}}{R T}}\left(X_{e q}-X\right)
$$

That way we have five equations with five variables $P, T, v, X, G_{g}$

\subsection{Initial Conditions}

The initial values to simulate each of the processes are taken from the final conditions of the previous process. For example, to simulate the desorption process the initial values of the concentration $X$, the temperature $T$ and the pressure $P$ are taken according to the final conditions of the adsorption process, considering that the carbon reached equilibrium with the methanol at nightly temperature.

The initial conditions for $X, Y, P$ are determined; The initial concentration value is calculated from the ideal gas state equation Furthermore, the initial concentration is calculated assuming that the device reached equilibrium during the previous night with a temperature of $0^{\circ} \mathrm{C}$ in the evaporator and ambient temperature throughout the absorber and $P$ is the pressure of vapour at ambient temperature.

\subsection{Boundary Conditions}

In the inner cylinder two boundary conditions are defined: one for the energy conservation equation and one for Darcy's law-absence of heat flow by conduction and pressure within the channel respectively.

$$
\left.\frac{\partial T}{\partial r}\right)_{r_{a}}=0
$$


The pressure inside the channel $\left(r=r_{a}\right)$ was defined as a function of time, constructed from the experimental data:

$$
P=\frac{50318}{\left(1+\mathrm{e}^{6.2588-0.00537 \frac{t}{60}}\right)^{0.3398}}
$$

With $t$ in seconds

On the outer surface of the absorber cylinder $r=r_{b}$, the boundary condition for the energy conservation equation is the surface temperature, which is defined as a function of time constructed from the experimental data.

$$
T=\frac{89.97}{\left(1+\mathrm{e}^{7.5063-0.0635 \frac{t}{60}}\right)^{0.16}}
$$

For the mass conservation equation, the zero velocity condition at the border is defined:

$$
v=0
$$

\subsection{Numerical Solution}

To obtain the solution of the system of equations presented, the discretization of each differential equation was done using the control volume method, an algorithm was elaborated, a program was written and the numerical solution was obtained.

The chosen control volume represents a hollow cylinder of radius $r$, wall thickness $d r$ and length $L$ Figure 3.

All the space occupied by the activated carbon is divided into $N$ control volumes as shown in Figure 4, where the nodes at the edges are surrounded by half control volume.

We assume that within each control volume all the searched variables $P, T, X$, $V$ and $G_{g}$ are constants in the volume (space). To discretize the derivative of the temperature in space is assumed linear staggered profile of temperature variation in space (variable $r$ ).

The solution of the energy conservation equation is obtained using the tridiagonal matrix algorithm TDMA (or Thomas algorithm) method and an implicit scheme when considering the temperature variation in the chosen time interval.

The numerical solution of our model allows to obtain the instantaneous values of the variables $P, T, X, v$ and $G_{g}$ for the whole cycle.

\section{Results and Discussion}

Figure 5 shows the prototype of the solar adsorption refrigerator, in which experimental data was obtained and posteriorly used for the validation of the constructed mathematical model.

Figure 6 shows the temperature distribution in the carbon bed. We can notice that 4 hours after the beginning of the desorption process the temperature 


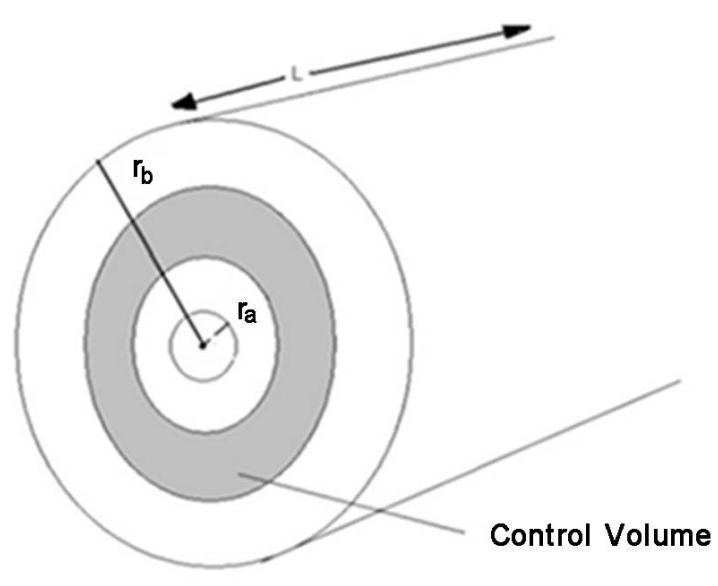

Figure 3. Scheme of the control volume in the absorber.

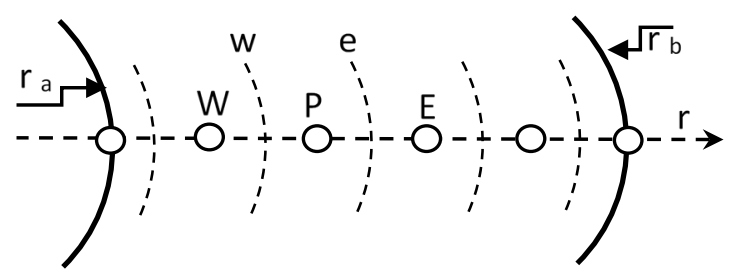

Figure 4. Division of the carbon bed in control volumes.

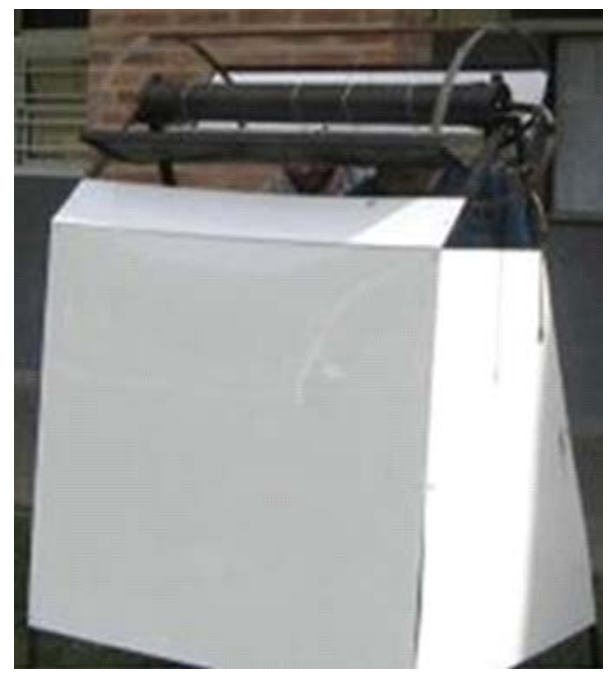

Figure 5. Experimental prototype.

on the outside of the absorber approaches the steady state, which corresponds to the measurements obtained by the authors in the experimental prototype. In other words, 4 - 5 hours after the start of the desorption process, the desorption stops and the amount of liquid methanol in the accumulator vessel no longer varies.

In the Figure 7 , it is presented the distribution of the adsorbed methanol concentration $X$ in the activated carbon for different times. In the graph, we observe a decrease of the concentration of methanol $X$ in the activated carbon. 


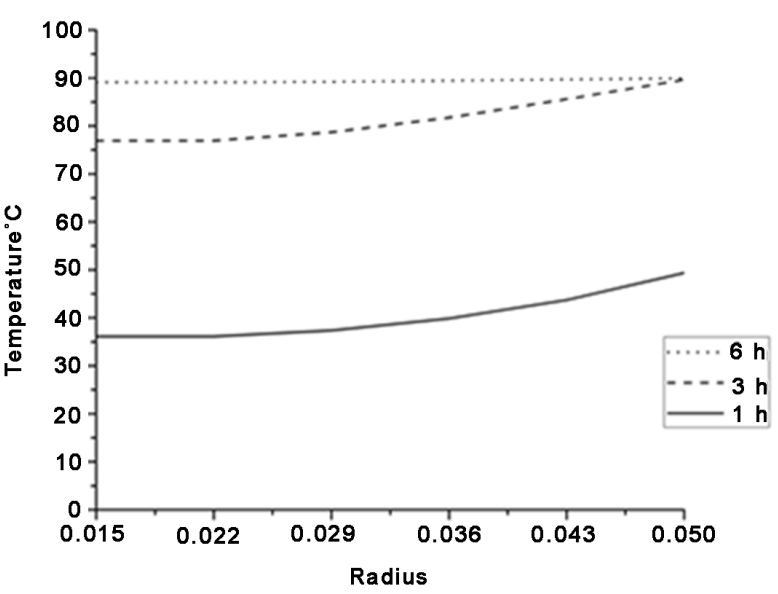

Figure 6. Distribution of temperatures in carbon bed.

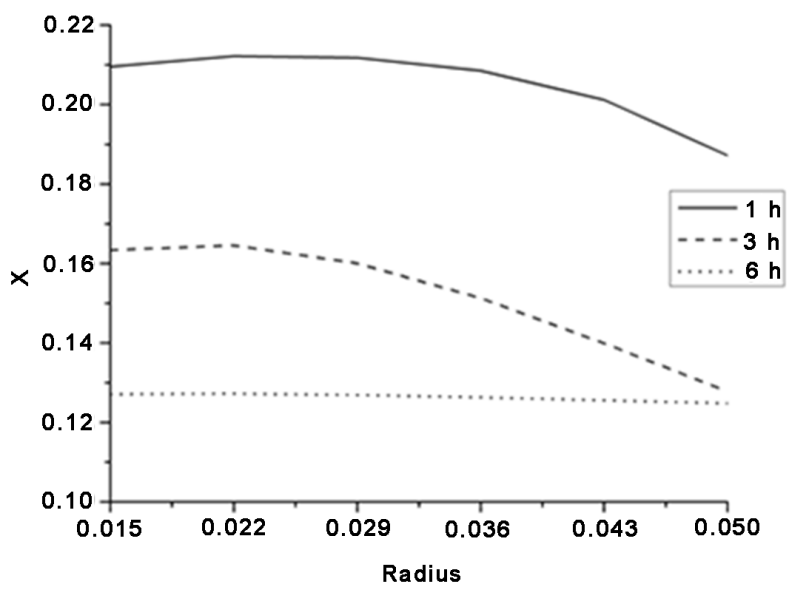

Figure 7. Amount of methanol adsorbed in carbon bed.

Four hours later, that concentration approaches the equilibrium values at the carbon temperature.

Integrating these results into the volume of carbon contained in the cylinder, and taking into account the initial concentration of methanol, we can obtain the amount of methanol desorbed during the isosteric heating process and during the desorption process.

The results of the calculations of the amount of desorbed methanol were compared with the experimental results for different days (Figure 8 and Figure 9).

We observe good coincidence between the theoretical and experimental curves during most of the time. Greater separation of the curves is observed in the first 1.5 hours of the desorption process. The most likely reason for the separation of the theoretical and experimental curves at the start of desorption, is due to the fact that the initial values of the temperature $T$ and concentration of methanol $X$ in the carbon bed are taken as constant values corresponding to the state of equilibrium according to the temperature of the previous night, whereas in the experiments these values depend on the previous processes. 


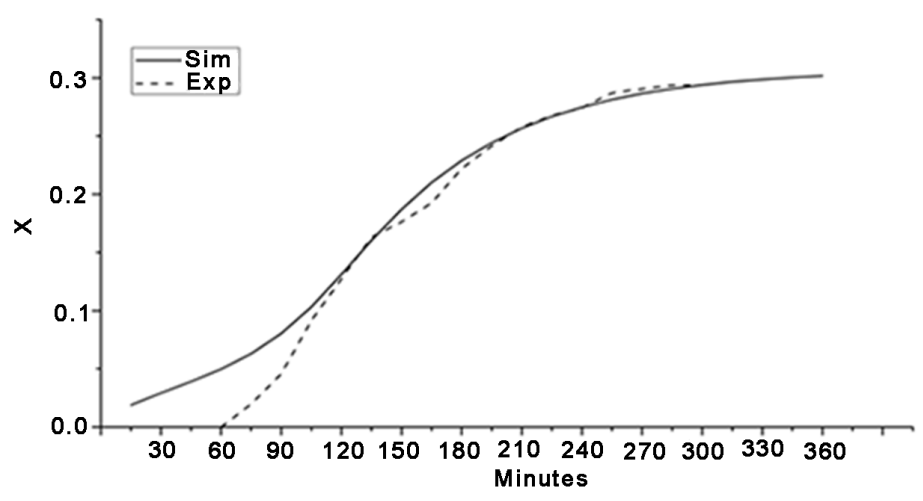

Figure 8. (a) Tcond $=20^{\circ} \mathrm{C}$ dash curve experimental and continuous simulated.

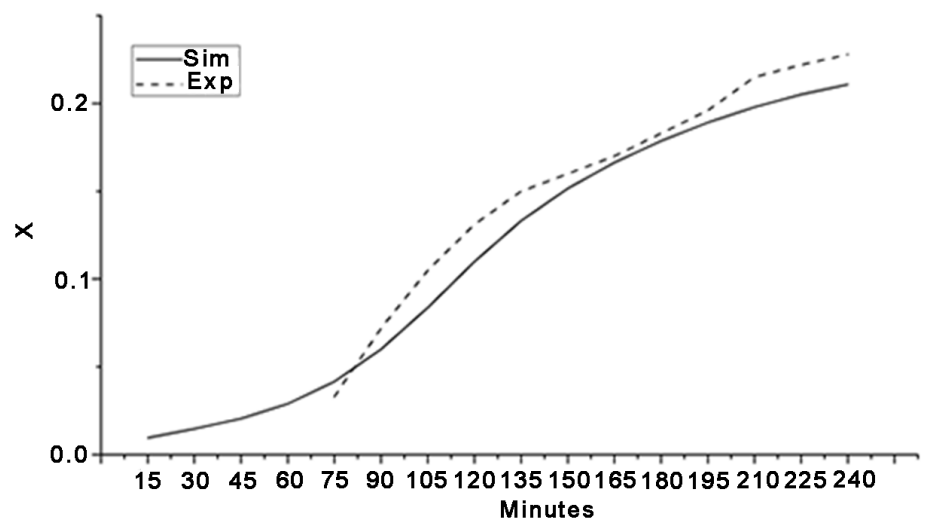

Figure 9. (b) Tcond $=30^{\circ} \mathrm{C}$ dash curve experimental and continuous simulated.

We do not have experimental data for higher ambient temperatures but the simulation indicates a drastic drop in ice production beyond $35^{\circ} \mathrm{C}$.

\section{Acknowledgements}

This work has been financially supported by the Ministerio de Educacion Superior, Ciencia y Tecnologia of Dominican Republic through projects INNOVACION 2012-2013-2E1-28 and 2015-2E4-091.

\section{References}

[1] Meunier, F. and Douss, N. (1990) Performance of Adsorption Heat Pumps; Active Carbon-Methanol and Zeolite-Water Pairs. ASHRAE Transactions, 96, 2.

[2] Wang, D., Li, Y., Li, D., Xia, Y. and Zhang, J. (2010) A Review on Adsorption Refrigeration Technology and Adsorption Deterioration in Physical Adsorption Systems. Renewable and Sustainable Energy Reviews, 14, 344-353.

https://doi.org/10.1016/j.rser.2009.08.001

[3] Tchernev, D. (1978) Solar Energy Application of Natural Zeolites. In: Sand, L.B. and Mumpton, F.A., Eds., Natural Zeolites: Occurrence, Properties and Use, Pergamon Press, Oxford, 479-485. 
[4] Tchernev, D. (1982) Solar Air Conditioning and Refrigeration Systems Utilizing Zeolites. Proceeding Meetings of IIR Commissions, E1-E2, Jerusalem, 209-215.

[5] Dupont, M., Guilleminot, J., Meunier, F. and Nguyen, P. (1982) Study of Solar Ice Conservators Using Day Night Intermittent Zeolite 13X-Water Cycle in Temperate and Tropical Climates. International Institute of Refrigeration, Jerusalem.

[6] Grenier, Ph., Gulleminot, J., Mester, M., Meunier, F. and Pons, M. (1983) Experimental Results on a 12 M2 Solar Powered Cold Store Using the Intermittent Zeolite 13X-Water Cycle. Proceedings of the ISES Conference, Perth, 14-19 August 1983, 353-357.

[7] Chua, H., Kim, C., Anutosh, C., Nay, M. and Chakraborty, O.M. (2002) Adsorption Characteristics of Silica Gel+ Water Systems. Journal of Chemical \& Engineering Data, 47, 1177-1181. https://doi.org/10.1021/je0255067

[8] Poyelle, F., Guilleminot, J. and Meunier, F. (1999) Experimental Tests and Predictive Model of an Adsorptive Air Conditioning Unit. Industrial \& Engineering Chemistry Research, 38, 298-309. https://doi.org/10.1021/ie9802008

[9] Vasiliev, L., Mishkinis, D. and Vasiliev, J.L. (1996) Multi-Effect Complex Compound/Ammonia Sorption Machines. Proceedings of the International Sorption Heat Pump Conferences, Motreal, 17-20 September, 3-8.

[10] Tamainot-Telto, Z. and Critoph, R. (2003) Advanced Solid Sorption Air Conditioning Modules Using Monolithic Carbon-Ammonia Pair. Applied Thermal Engineering, 23, 659-674. https://doi.org/10.1016/S1359-4311(02)00238-7

[11] Critoph, R. (1994) An Ammonia Carbon Solar Refrigerator for Vaccine Cooling. Renewable Energy, 5, 502-508. https://doi.org/10.1016/0960-1481(94)90424-3

[12] Critoph, R. (1998) Forced Convection Adsorption Cycles. Applied Thermal Engineering, 18, 799-807. https://doi.org/10.1016/S1359-4311(97)00110-5

[13] Jones, J.A. (1993) Carbon/Ammonia Regenerative Adsorption Heat Pump. Proceedings of International Absorption Heat Pump Conference, 31, 449-455.

[14] Tubreoumya, G.C., Dissa, A.O., Tiendrebeogo, E.S., Chesneau, X., Compaoré, A., Haro, K., Konseibo, C.D., Zeghmati, B. and Koulidiati, J. (2017) Contribution to the Modeling of a Solar Adsorption Refrigerator under the Climatic Conditions of Burkina Faso. Energy and Power Engineering, 9, 119-135. https://doi.org/10.4236/epe.2017.92010

[15] Allouhi, A., Kousksou, T., Jamil, A., El Rhafiki, T., Mourad, Y. and Zeraoul, Y. (2015) Optimal Working Pairs for Solar Adsorption Cooling Applications. Energy, 79, 235-247. http://doi.org/10.1016/j.energy.2014.11.010

[16] Qasem, N. and El-Shaarawi, M. (2013) Improving Ice Productivity and Performance for an Activated Carbon/Methanol Solar Adsorption Ice-Maker. Solar Ener$g y$, 98, 523-542. https://doi.org/10.1016/j.solener.2013.10.018

[17] Vasiliev, L., Mishkinis, D. and Vasiliev, J.L. (2001) Solar-Gas Solid Sorption Heat Pump. Applied Thermal Engineering, 21, 573-583. https://doi.org/10.1016/S1359-4311(00)00069-7

[18] Boubakri, A., Guilleminot, J. and Meunier, F. (2000) Adsorptive Solar Powered Ice Maker: Experiments and Model. Solar Energy, 69, 249-263. https://doi.org/10.1016/S0038-092X(00)00063-3

[19] Anyanwu, E. and Ogueke, N. (2007) Transient Analysis and Performance Prediction of a Solid Adsorption Solar Refrigerator. Applied Thermal Engineering, 27, 2514-2523. https://doi.org/10.1016/j.applthermaleng.2007.02.002

[20] Luo, L. and Tondeur, D. (2000) Transient Thermal Study of an Adsorption Refrige- 
rating Machine. Adsorption, 6, 93-104. https://doi.org/10.1023/A:1008907518073

[21] Leite, A., Becerra Grilo, M., Duarte Andrade, R., Belo, F. and Meunier, F. (2005) Experimental Evaluation of a Multi-Tubular Adsorber Operating with Activated Carbon-Methanol. Adsorption, 11, 543-548.

https://doi.org/10.1007/s10450-005-5982-8

[22] Leite, A.P.F., Grilo, M.B., Andrade, P.R.D., Belo, F.A. and Meunier, F. (2007) Experimental Thermodynamic Cycles and Performance Analysis of a Solar-Powered Adsorptive Icemaker in Hot Humid Climate. Renewable Energy, 32, 697-712. https://doi.org/10.1016/j.renene.2006.03.002

[23] Zhao, Y., Hu, E. and Blazewicz, A. (2012) Dynamic Modelling of an Activated Carbon-Methanol Adsorption Refrigeration Tube with Considerations of Interfacial Convection and Transient Pressure Process. Applied Energy, 95, 276-284. https://doi.org/10.1016/j.apenergy.2012.02.050

[24] Zhang, L. (2000) A Three-Dimensional Non-Equilibrium Model for an Intermittent Adsorption Cooling System. Solar Energy, 69, 27-35. https://doi.org/10.1016/S0038-092X(00)00010-4

[25] Khan, M.A., Sultana, S., Akisawa, A. and Kashiwagi, T. (2006) Numerical Simulation of Advanced Adsorption Refrigeration Chiller with Mass Recovery. Journal of Naval Architecture and Marine Engineering, 3, 59-67. http://doi.org/10.3329/jname.v3i2.920

\section{Nomenclature}

\begin{tabular}{|c|c|c|c|}
\hline Sym & Comment & Sym & Comment \\
\hline$\beta$ & Affinity coefficient in D. A equation & $r_{a}$ & Inner radius of absorber \\
\hline$\varepsilon$ & $\begin{array}{c}\text { Volume of the empty space between } \\
\text { the carbon pellets in relation to total } \\
\text { volume }\end{array}$ & $r_{b}$ & Outer radius of absorber \\
\hline$\rho_{c}$ & Activated carbon density & $R_{p}$ & Carbon particle radius \\
\hline$\mu$ & Coefficient of viscosity & $t$ & Time \\
\hline$C_{g}$ & Gas concentration & $T$ & Temperature \\
\hline$D_{0}$ & Diffusion coefficient & $U_{a d s}$ & Adsorption energy \\
\hline$E_{a}$ & Activation energy & $U_{c}$ & Internal energy of activated carbon \\
\hline$h_{g}$ & Enthalpy of gas & $U_{g}$ & Internal energy of gas \\
\hline$K_{d}$ & Darcy's coefficient & $U_{\text {met }}$ & Internal energy of methanol \\
\hline$K_{\text {eff }}$ & $\begin{array}{l}\text { Conduction coefficient of carbon } \\
\text { with adsorbed methanol }\end{array}$ & V & Gas velocity \\
\hline$n$ & $\begin{array}{l}\text { Characteristic parameter of } \\
\text { adsorption pair }\end{array}$ & $X$ & $\begin{array}{l}\text { Methanol concentration on activated } \\
\text { carbon }\end{array}$ \\
\hline$P$ & Gas pressure & $X_{0}$ & Maximun adsorption capacity \\
\hline$P_{0}$ & Saturation pressure of methanol & $X_{e q}$ & Equilibrium concentration of methanol \\
\hline$r$ & Radius & & \\
\hline
\end{tabular}


Submit or recommend next manuscript to SCIRP and we will provide best service for you:

Accepting pre-submission inquiries through Email, Facebook, LinkedIn, Twitter, etc. A wide selection of journals (inclusive of 9 subjects, more than 200 journals)

Providing 24-hour high-quality service

User-friendly online submission system

Fair and swift peer-review system

Efficient typesetting and proofreading procedure

Display of the result of downloads and visits, as well as the number of cited articles Maximum dissemination of your research work

Submit your manuscript at: http://papersubmission.scirp.org/

Or contact epe@scirp.org 